\title{
Repeatability of airway deposition and tracheobronchial clearance rate over three days in chronic bronchitis
}

\author{
C.H. Ericsson*, K. Svartengren**, M. Svartengren+\#, B. Mossberg*, \\ K. Philipson+, M. Blomquist*, P. Camner ${ }^{+}$
}

Repeatability of airway deposition and tracheobronchial clearance rate over three days in chronic bronchitis. C.H. Ericsson, K. Svartengren, M. Svartengren, B. Mossberg, K. Philipson, M. Blomquist, P. Camner. @ERS Journals Ltd 1995.

ABSTRACT: Previous investigations on tracheobronchial clearance in chronic bronchitis or chronic obstructive pulmonary disease (COPD) have usually referred to measurements during a short time-period, i.e. a few hours. The purpose of this study, therefore, was to study regional particle deposition and tracheobronchial clearance during $72 \mathrm{~h}$.

In 14 patients with chronic bronchitis clearance of 111 In-labelled $3.6 \mu \mathrm{m}$ Teflon particles and lung function were measured on two occasions, with an interval of 2 weeks. Lung retention of test particles was measured at $0,24,48$ and $72 \mathrm{~h}$ using a profile scanner. The weight of expectorated sputum samples was measured after the two clearance measurements.

The particle retentions at all time-points were reproducible, as seen from the two measurements $(r>0.90)$. The fast clearance phase was completed within $72 \mathrm{~h}$. No correlation between sputum volume and clearance was seen. There was a significant negative correlation between airway resistance and the $72 \mathrm{~h}$ retention $(r=-0.66)$, and an even better correlation between specific airway resistance and the $72 \mathrm{~h}$ retention $(\mathrm{r}=-\mathbf{0 . 8 2})$, indicating more central deposition in obstructed airways. There was no significant correlation between lung function tests reflecting smaller airways and the $72 \mathrm{~h}$ retentions. Deposition data agreed well with theoretical calculations and experimental data in healthy subjects.

In spite of earlier findings that mucociliary transport is usually severely impaired in chronic bronchitis and COPD, the present results indicate that overall tracheobronchial mucus clearance in these patients is fairly effective, probably due to a productive cough. Alveolar deposition may be estimated by measurements of the $72 \mathrm{~h}$ retention in subjects with chronic obstructive pulmonary disease. The $72 \mathrm{~h}$ retention is dependent mainly on the calibre of larger airways. The present method of studying airway clearance during 3 days is highly reproducible.

Eur Respir J., 1995, 8, 1886-1893.

\begin{abstract}
*Dept of Respiratory Medicine and Allergology, Karolinska Institute, Stockholm Söder Hospital, Stockholm, Sweden. **Dept of Respiratory and Allergic Diseases, Karolinska Institute, Huddinge University Hospital, Huddinge, Sweden. +Division of Inhalation Toxicology, Unit of Environmental Hygiene, Institute of Environmental Medicine, Karolinska Institute, Stockholm, Sweden. \#Depts of Occupational Medicine and of Medicine, Karolinska Institute, Huddinge University Hospital, Huddinge, Sweden.
\end{abstract}

Correspondence: C.H. Ericsson, Dept of Respiratory Medicine and Allergology, (Lung\& Allergikliniken), Stockholm Söder Hospital, S-118 83 Stockholm, Sweden

Keywords: Cough

lung function

lung retention

mucociliary clearance

mucus

Received: June 301994

Accepted after revision June 301995

This work was supported by grants from the National Swedish Environmental Protection Board, the Swedish Heart Lung Foundation, the Herman Krefting Allergy and Asthma Research Fund, and Draco AB.
The lower airways are mechanically cleared of inhaled particles mainly by two mechanisms: mucociliary clearance (MC) and cough. MC is an important defence mechanism of the airways, which has been demonstrated by investigation of persons with immotile cilia syndrome (ICS) $[1,2]$. Such persons have chronic or recurrent infections of the upper and lower airways from early childhood, and often develop bronchiectasis and obstructive lung disease. In this condition, the MC is obviously primarily affected. In other conditions, a main difficulty in evaluating the role of an impaired MC has been to judge whether an observed impaired clearance is the cause or result of the disease (or both) [3].

Most patients with chronic obstructive pulmonary disease (COPD) have a severely impaired MC, and this is also more or less the case in patients with chronic bronchitis without apparent airways obstruction [4-7]. Furthermore, healthy or symptomless smokers often have a certain impairment of clearance [6-9]. It has, therefore, been suggested that an impaired $\mathrm{MC}$ is an important pathogenetic factor in the development of COPD, as must be true for cases of airflow obstruction in ICS [3].

Irritation and inflammation of the airways leads to increased mucus production as well as cough, and an increased amount of mucus plays an important role in the clearance produced by coughing [2, 4, 10-12]. Recently, RuUSA et al. [13] showed that more than $80 \%$ of inhaled $6 \mu \mathrm{m}$ Teflon particles were cleared within $72 \mathrm{~h}$ in patients with ICS, probably a demonstration of the significance of cough. The efficacy of coughing shows great variation among patients. For example, patients with ICS eliminated $2-48 \%$ of inhaled test particles by 
voluntary coughing during a few minutes [2]. Although an increased amount of tracheobronchial secretion seems to be necessary for coughing to be effective, it remains obscure what amount or rheological properties of mucus are optimal for cough clearance.

Measurements of whole lung clearance in healthy subjects, using inhaled radiolabelled test aerosols, have demonstrated a rapid clearance phase, often reported to be completed within $24 \mathrm{~h}[14,15]$. The rapidly cleared fraction has generally been equated with tracheobronchial deposition and the retained fraction with alveolar deposition (i.e. deposition in the gas-exchange region). Among healthy subjects, there are wide variations in particle deposition [14-16], but for a given subject deposition is fairly reproducible [15-17].

Alveolar deposition can, thus, be estimated as the percentage retention of inhaled particles after $24 \mathrm{~h}$ (Ret24), or even after $6 \mathrm{~h}$ (Ret6) when mucociliary clearance is stimulated by inhalation of a cholinergic aerosol [18]. A significant negative correlation between airway resistance (Raw) and alveolar deposition has been found in healthy subjects [17, 19] and asthmatics [20, 21]. Furthermore, particles have been found to be more centrally deposited in the tracheobronchial region in patients with obstructive airway diseases, such as asthma and ICS, than in healthy subjects even at corresponding $R$ aw values $[13,20]$. One tentative explanation for this could be that changes in smaller airways are also important for tracheobronchial deposition, as asthmatics and ICS patients show significant correlations between lung retention and lung function parameters reflecting changes in smaller airways, such as forced expiratory flow at 75$85 \%$ of forced vital capacity (FEF75-85\%) and singlebreath $\mathrm{N}_{2}$ test phase III [13, 21, 22]. Another possible explanation might be a generally more turbulent flow in diseased compared to healthy airways, with the rough surfaces enhancing deposition [18, 23].

Earlier investigations in subjects with chronic bronchitis and/or COPD have studied tracheobronchial clearance during rather short time-periods, usually $2-6 \mathrm{~h}$ and occasionally $24 \mathrm{~h}$, during which time the fast clearance phase may not always be completed [4-7, 24]. AGNEw et al. [25] reported a study on clearance in 10 patients with COPD where the mean fall in retention from 24 to $48 \mathrm{~h}$ was $6.5 \%$ of the initial deposition. Little is known about tracheobronchial clearance in COPD or chronic bronchitis during a longer period of time (days). The aim of the present study was to investigate tracheobronchial clearance, i.e. the combined effects of mucociliary transport and clearance by cough, during $72 \mathrm{~h}$ in such patients, in order to determine when the fast clearance phase was completed and to study its reproducibility. We also studied the association between sputum volumes and clearance, to see if an increased amount of sputum is correlated to faster clearance. Finally, we examined the relationships between percentage retention of inhaled particles after $72 \mathrm{~h}$ (Ret72) and lung function parameters reflecting dimensions of large airways $(R \mathrm{aw})$ and small airways (FEF75-85\% and $\mathrm{N}_{2}$ test). The size of the particles used is common in the occupational and general environment, as well as in therapeutic situations.
Methods

\section{Selection procedure and inclusion criteria}

Patients with a history of chronic bronchitis and varying degree of airways obstruction were recruited from two clinics for respiratory diseases in the urban area of Stockholm. The subjects were smokers or ex-smokers with a history of chronic bronchitis, i.e. they had current bronchitic symptoms or had previously had such symptoms. Chronic bronchitis was defined according to the British Medical Research Council (MRC) criteria, i.e. cough and expectoration during at least three consecutive months of each of the preceding 2 yrs [26]. The subjects had mild to moderately severe airways obstruction with forced expiratory volume in one second (FEV1) $<80 \%$ of predicted before the study. Forced vital capacity (FVC) should be at least $1.7 \mathrm{~L}$ to allow the subjects to inhale a sufficient volume in connection with the clearance measurements. Symptoms had to be relatively stable in the 4 weeks prior to the study, with no purulent exacerbation. Subjects with asthma or suspected asthma and those with reversible airways obstruction were excluded, as were those with serious medical or psychiatric complaints. All subjects gave informed consent to participate in the study, which was approved by the Ethics Committee on Human Research of the Karolinska Institute, Stockholm, Sweden.

\section{Clinical investigations}

All subjects were investigated during springtime (MarchMay). On the first occasion, they were interviewed by a chest physician concerning smoking history, airway symptoms (cough, expectoration, breathlessness, wheezing etc.), recent airway infections, other diseases and current medication. Lung function for inclusion in the study was measured using a Vitalograph dry bellows spirometer. Fourteen subjects fulfilled the inclusion criteria and volunteered for the study. One to two months later, tracheobronchial clearance and lung function parameters were measured on two occasions, with a 2 week interval. On three occasions, sputum samples were collected and weighed. The subjects continued their medical therapy throughout the study. Thirteen subjects were studied twice and one subject once.

\section{Subjects}

Personal and lung function data of the 14 subjects included, as determined during the study, are given in table 1. There were five men and nine women, with an average age of 59 yrs (range 37-71 yrs). At examination after inclusion mean FEV1 after bronchodilatation was $1.46 \mathrm{~L}$ (range 0.85-2.75 L), 52\% (range 16-87\%) of predicted normal value. Four subjects were current smokers and 10 were ex-smokers (table 2). The average smoking history was 29 (range 14-62) pack-years. 
Table 1. - Personal and lung function data

\begin{tabular}{|c|c|c|c|c|c|c|c|c|c|c|}
\hline \multirow[b]{2}{*}{$\begin{array}{l}\text { Subject } \\
\text { No. }\end{array}$} & \multirow[b]{2}{*}{ Sex } & \multirow[b]{2}{*}{$\begin{array}{l}\text { Age } \\
\text { yrs }\end{array}$} & \multirow[b]{2}{*}{$\begin{array}{c}\text { Height } \\
\mathrm{cm}\end{array}$} & \multirow[b]{2}{*}{$\begin{array}{l}\text { Weight } \\
\text { kg }\end{array}$} & \multicolumn{2}{|c|}{ FEV1 } & \multicolumn{2}{|c|}{ FVC } & \multirow[b]{2}{*}{$\begin{array}{c}R \text { aw } \\
\mathrm{cmH}_{2} \mathrm{O} \cdot \mathrm{L}^{-1} \cdot \mathrm{s}\end{array}$} & \multirow[b]{2}{*}{$\begin{array}{c}\mathrm{sRaw} \\
\mathrm{cmH}_{2} \mathrm{O} \cdot \mathrm{s}\end{array}$} \\
\hline & & & & & $\mathrm{L}$ & $\%$ pred* & $\mathrm{L}$ & $\%$ pred* & & \\
\hline 1 & F & 65 & 157 & 48 & 0.86 & 44 & 1.92 & 81 & 3.3 & 15.5 \\
\hline 2 & M & 61 & 170 & 68 & 1.18 & 39 & 2.47 & 64 & 2.9 & 13.7 \\
\hline 3 & $\mathrm{~F}$ & 65 & 162 & 64 & 1.53 & 70 & 2.45 & 98 & 3.4 & 12.9 \\
\hline 4 & M & 71 & 176 & 65 & 1.09 & 27 & 2.83 & 73 & 2.8 & 14.6 \\
\hline 5 & $\mathrm{~F}$ & 58 & 166 & 55 & 1.25 & 50 & 2.66 & 90 & 3.2 & 16.3 \\
\hline 6 & $\mathrm{~F}$ & 64 & 160 & 54 & 1.04 & 49 & 2.11 & 83 & 3.4 & 19.4 \\
\hline 7 & $\mathrm{~F}$ & 59 & 171 & 59 & 2.17 & 83 & 3.14 & 101 & 1.7 & 6.3 \\
\hline 8 & F & 60 & 169 & 63 & 1.13 & 43 & 2.09 & 68 & 3.6 & 13.6 \\
\hline 9 & $\mathrm{~F}$ & 54 & 170 & 54 & 1.54 & 56 & 3.01 & 93 & 2.3 & 11.2 \\
\hline 10 & $\mathrm{~F}$ & 46 & 176 & 92 & 2.27 & 71 & 3.07 & 84 & 2.1 & 6.4 \\
\hline 11 & M & 63 & 172 & 80 & 1.01 & 31 & 2.76 & 67 & 3.1 & 25.3 \\
\hline 12 & $\mathrm{M}$ & 57 & 190 & 94 & 0.99 & 25 & 3.56 & 71 & 3.2 & 28.0 \\
\hline 13 & $\mathrm{~F}$ & 67 & 170 & 68 & 1.18 & 48 & 2.41 & 83 & 3.0 & 17.9 \\
\hline 14 & M & 37 & 177 & 68 & 2.99 & 75 & 4.36 & 91 & 1.6 & 7.0 \\
\hline Mean & & 59 & 170 & 66 & 1.44 & 51 & 2.77 & 82 & 2.8 & 14.9 \\
\hline SD & & 9 & 8 & 14 & 0.61 & 18 & 0.64 & 12 & 0.7 & 6.5 \\
\hline
\end{tabular}

*: predicted values according to QUANJER [27]. FEV1: forced expiratory volume in one second; FVC: forced vital capacity; Raw: airways resistance; sRaw: specific airways resistance; F: female; M: male; \% pred: percentage of predicted.

Table 2. - History of chronic bronchitis and smoking, and current medication in 14 subjects with chronic bronchitis

\begin{tabular}{cclll}
\hline $\begin{array}{l}\text { Subject } \\
\text { No. }\end{array}$ & $\begin{array}{c}\text { Duration of } \\
\text { chronic } \\
\text { bronchitis } \\
\text { yrs }\end{array}$ & $\begin{array}{c}\text { Smoking } \\
\text { status }\end{array}$ & $\begin{array}{c}\text { Pack- } \\
\text { years }\end{array}$ & $\begin{array}{c}\text { Current } \\
\text { medication }\end{array}$ \\
\hline 1 & 5 & Ex-smoker, 7 yrs & 17 & OT+IB+IC+IA \\
2 & 12 & Ex-smoker, 1 yr & 42 & OT+IB+M \\
3 & 3 & Smoker & 55 & - \\
4 & 2 & Ex-smoker, 7 yrs & 20 & OT+IB+IC+OB \\
5 & 3 & Smoker & 56 & IB+IC+M \\
6 & 15 & Smoker & 14 & IA+M \\
7 & 2 & Smoker & 30 & OT+IB+IA+IC+M \\
8 & 5 & Ex-smoker, 2 yrs & 26 & IB+M \\
9 & 2 & Ex-smoker, 1 yr & 14 & OT+M \\
10 & 2 & Ex-smoker, 8 yrs & 14 & OT+IB+IA+M \\
11 & 11 & Ex-smoker, 2 yrs & 20 & IB \\
12 & 7 & Ex-smoker, 2 yrs & 62 & IB+M \\
13 & 11 & Ex-smoker, 2 yrs & 22 & 18 \\
14 & 20 & Ex-smoker, 2 yrs & 18 & \\
\hline
\end{tabular}

IB: inhaled beta-agonists; OB: oral beta-agonists; IC: inhaled corticosteroids; M: mucolytics; OT: oral theophylline; IA: inhaled anticholinergics.

Twelve out of 14 subjects were on current medication for their airway disease (table 2). Twelve patients had a history of current chronic bronchitis for, on average, 6.5 yrs (range 2-20 yrs) (table 2). Two patients (Nos. 11 and 13) had had symptoms of chronic bronchitis for many years, but these symptoms more or less disappeared after they stopped smoking 2 years earlier.

\section{Aerosol exposure and measurements of radioactivity}

Monodisperse Teflon particles with an aerodynamic diameter of $3.6 \mu \mathrm{m}$ were produced and labelled with ${ }^{111} \mathrm{In}$ (half-life $68 \mathrm{~h}$ ) by a spinning disc technique [28, 29].
The particles were suspended in water $(0.7 \mathrm{mg}$ particles $\cdot \mathrm{mL}^{-1}$ ), and $0.2 \mathrm{~mL}$ of the suspension was sprayed up 2-3 times into a $25 \mathrm{~L}$ glass bulb with a jet spray (Beckman Atomizer). The subjects inhaled the particles with 8-10 maximally deep inhalations at a flow of $0.5 \mathrm{~L} \cdot \mathrm{s}^{-1}$ during 3-5 min, with a pause of 1-2 s between inhalation and exhalation. The flow was measured with a pneumotachograph positioned between the bulb and the mouthpiece and was recorded graphically. The subjects were trained to inhale at a fairly constant flow rate throughout the inspiration. In order to collect exhaled particles, the exhalations during exposure were performed through a low-resistance filter. The amount of exhaled particles was less than $2 \%$ of the inhaled radioactivity. 
The radioactivity was measured using two $13 \times 5 \mathrm{~cm}$ $\mathrm{NaI}$ crystals fitted with collimators which profile scanned over the supine subjects [28]. The radioactivity over mouth and throat, lungs and stomach was measured twice immediately after the inhalation of the test particles, and 24, 48 and $72 \mathrm{~h}$ later measurements were repeated over the lungs. Corrections were made for natural decay of the radionuclide. Regional deposition was estimated by adjusting the gamma counts registered in the mouth and throat, lungs and stomach to absolute values using factors for self-absorption obtained from measurements in a phantom (Average Man Rando Phantom, Alderson Research Laboratories). Compared to air, self-absorption was on average about 2 for head and throat, 2.5 for the lungs, and 4 for the stomach $[30,31]$. The total inhaled activity was obtained by adding the activities from an exhalation filter (Inspiron ${ }^{\circledR}$, C.R. Bard Inc., CA, USA). The Ret72 of the initial amount of particles deposited in the lungs were correlated to lung function parameters reflecting changes in larger and smaller airways (see below).

\section{Lung function measurements}

For inclusion in the study, FVC and FEV1 were measured with the subjects in standing position, using a Vitalograph spirometer, before and $20 \mathrm{~min}$ after bronchodilatation with either salbutamol $400 \mu \mathrm{m}$ or terbutaline $500 \mu \mathrm{m}$ in a spacer. During the study, lung function tests were performed before both exposures on the same day as the inhalation of test particles. FVC, FEV1, flowvolume loops (FEF75-85\%), and single-breath oxygen $\left(\mathrm{sbO}_{2}\right)$-test were measured using a Lung Function Laboratory 2100 (SensorMedics, USA) with the subjects in a sitting position wearing a noseclip. During $\mathrm{sbO}_{2}$ test, $\mathrm{N}_{2}$ was continuously monitored, the slope of Phase III $\left(\mathrm{N}_{2}\right.$-delta) was calculated. $R$ aw and thoracic gas volume (TGV) were measured during panting in the whole-body plethysmograph Transmural Body Box 2800 (SensorMedics, USA). Box pressure was calibrated twice daily. All lung function parameters were determined according to the criteria proposed by QUANJER [27]. Mean values were used in the calculations of relationships between lung function data and Ret72.

\section{Sputum collections}

After inclusion in the study, the subjects underwent physiotherapy by a trained chest physiotherapist on one occasion. The physiotherapy programme consisted of five different standardized breathing exercises for removing tracheobronchial secretions. During this $30 \mathrm{~min}$ programme all expectorated sputum was collected. The weight of wet sputum was measured by electronic scale. The aim of this procedure was to teach the subjects how to collect sputum in special double cans with airtight covers to avoid water evaporation. The subjects were trained to avoid sampling saliva.

Sputum was also collected by the subjects on two occasions in their homes after each clearance experiment, 1 or 2 days after the $72 \mathrm{~h}$ retention measurements. During the first two morning hours after leaving bed, the subjects collected all expectorated sputum, which was sent to the clinic and weighed.

\section{Statistical analysis}

Linear regression analysis was used for evaluation of correlation between lung retention and lung function, and sputum weight and lung retention or clearance. Retention data were analysed using paired t-test. Wilcoxon two-tailed signed rank test was used to evaluate whether differences in retention between exposures were related to Raw.

\section{Results}

\section{Clinical data and sputum weights}

There was a reasonable agreement between the sputum weights after physiotherapy and those collected in the subjects' homes; but there were three exceptions, subjects Nos. 8, 10 and 11, and no statistical correlation could be detected $(\mathrm{p}>0.05)$. The weights of the sputum samples collected after each of the clearance measurements were highly correlated $(\mathrm{r}=0.87 ; \mathrm{p}<0.02)$ (fig. 1$)$.

\section{Tracheobronchial clearance}

Lung retentions over the 3 day period for each of the 14 subjects are presented in figure 2 . The average lung retentions are given in figure 3 . The retentions at all time-points were reproducible at the two measurements $(\mathrm{r}>0.90 ; \mathrm{p}<0.01)$. The $24 \mathrm{~h}$ retentions were $56.4 \pm 16.0 \%$ (mean \pm SD) and $55.5 \pm 13.3 \%$, respectively, the $48 \mathrm{~h}$ retentions were $50.6 \pm 16.1 \%$ and $51.0 \pm 13.0 \%$, respectively, and the $72 \mathrm{~h}$ retentions were $48.0 \pm 14.0 \%$ and $47.9 \pm 12.9 \%$, respectively. Tracheobronchial clearance (in percentage

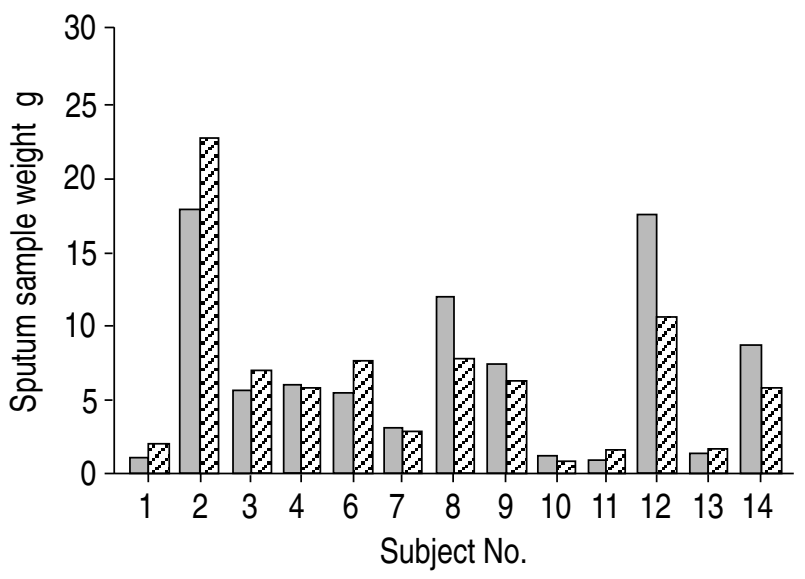

Fig. 1. - The weights of the sputum samples collected during two early morning hours after first ( $\square$ ) and second ( $\square$ ) clearance measurements, respectively, in the 13 subjects with chronic bronchitis who were examined twice. 

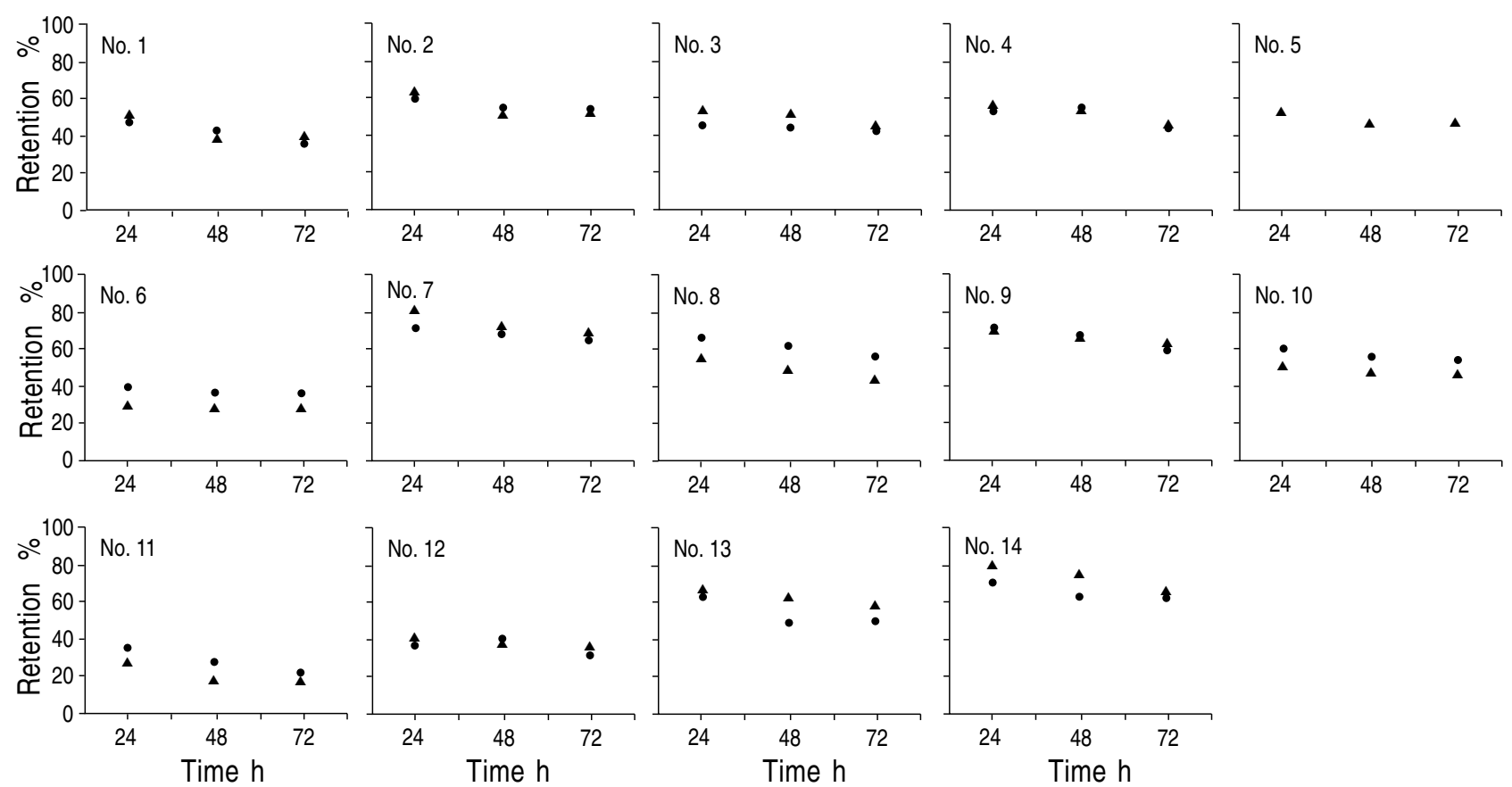

Fig. 2. - Retention of inhaled $3.6 \mu \mathrm{m}$ Teflon particles in 14 subjects with chronic bronchitis over time. $\Delta$ : first clearance measurement; second clearance measurement.

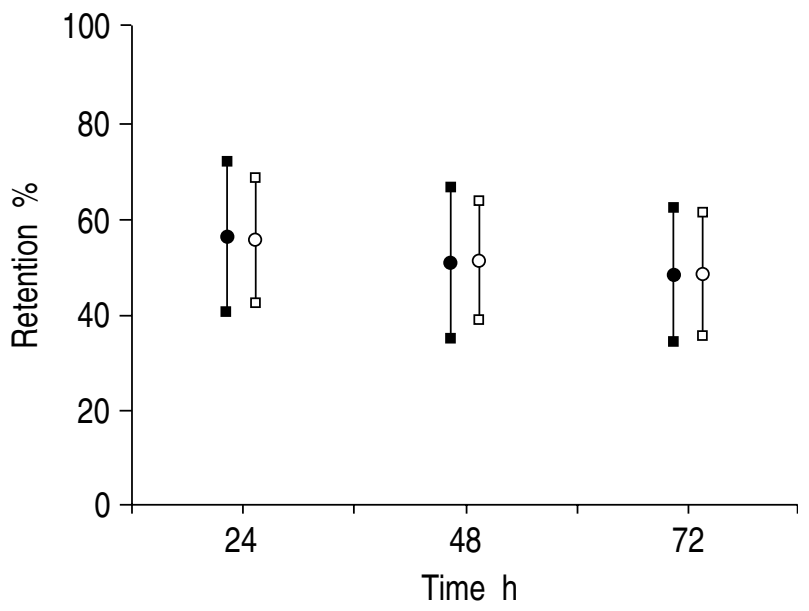

Fig. 3. - The mean retention of $3.6 \mu \mathrm{m}$ Teflon particles in 13 subjects with chronic bronchitis (mean \pm SD). Solid symbols: first measurement; open symbols: second measurement.

of the total amount of particles cleared during $72 \mathrm{~h}$ ) after $24 \mathrm{~h}$ was $81.7 \pm 10.9 \%$ and $84.7 \pm 8.4 \%$, respectively, and clearance after $48 \mathrm{~h}$ was $93.8 \pm 8.7 \%$ and $93.9 \pm 6.4 \%$, respectively. The $24 \mathrm{~h}$ retentions were highly correlated with the $72 \mathrm{~h}$ retentions at both clearance measurements ( $\mathrm{r}=0.98$ and $\mathrm{r}=0.95$, respectively). We could not detect any correlation between $24 \mathrm{~h}$ tracheobronchial clearance and sputum weight, nor between $72 \mathrm{~h}$ retention and sputum weight.

\section{Lung function and deposition}

Mouth and throat deposition of the inhaled particles ranged $8-37 \%$. The mean \pm SD values for the two exposures were $16 \pm 5 \%$ and $17 \pm 8 \%$, and the values within the subjects were significantly correlated $(\mathrm{r}=0.66 ; \mathrm{p}<0.05)$.
The Ret72 values, considered to represent alveolar deposition of particles, were normally distributed (fig. 4). There was a significant negative correlation between $R$ aw and $\operatorname{Ret} 72$ (r=-0.66; $\mathrm{p}<0.05)$ (fig. 5). For comparison, corresponding theoretical deposition data and data found previously in healthy subjects [18] are included in figure 5. Theoretical data are based on the model by the Task Group on Lung Dynamics [32]. The model was modified so that the diameters of all airway generations could be changed, and both airway resistance and deposition could be calculated for each generation for any flow rate and particle size [17, 18, 20, 33]. For healthy subjects, the $6 \mathrm{~h}$ retention values (Ret6) at corresponding flow rate and particle size are given in figure 5.

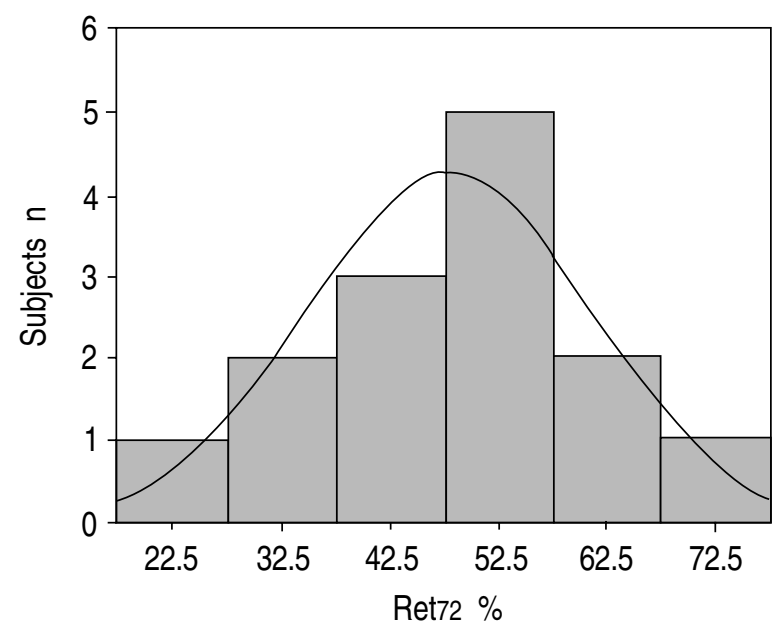

Fig. 4. - Alveolar deposition: distribution of retentions of inhaled $3.6 \mu \mathrm{m}$ particles at $72 \mathrm{~h}$ (Ret72) in 14 subjects with chronic obstructive bronchitis. The mean \pm SD was $48 \pm 13 \%$ for both exposures. 


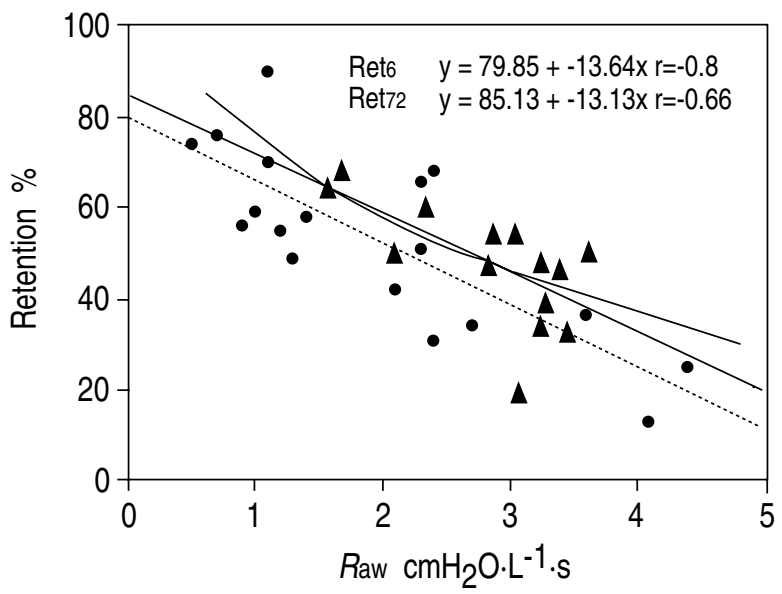

Fig. 5. - Correlation between airway resistance (Raw) and the percentage retention of $3.6 \mu \mathrm{m}$ particles at $72 \mathrm{~h}$ (Ret72) in subjects with chronic obstructive bronchitis. For comparison, corresponding data from percentage retention at $6 \mathrm{~h}$ (Ret6) in healthy subjects and theoretical calculations (curved line) are included in the diagram. $\cdots$ Ret6; — : Ret72; $:$ theoretical.

These values were obtained when clearance was stimulated by a cholinergic aerosol. It is shown that experimental and theoretical data are in good agreement. The correlation between FEV1 and Ret72 was similar to that between Ret72 and Raw (r=0.66). Among the lung function parameters, specific airway resistance ( $\mathrm{s} R \mathrm{aw}$ ) was found to be the best predictor of Ret72 $(\mathrm{r}=-0.82)$. A sRaw value of 5 and $25 \mathrm{cmH}_{2} \mathrm{O} \cdot \mathrm{s}$ corresponded to an alveolar deposition of about 65 and $30 \%$, respectively. Also, data in chronic bronchitic patients agree with corresponding data in healthy subjects [18].

The mean \pm SD of the absolute individual differences in Ret72 between the two exposures was $5 \pm 3 \%$. The Ret72 value was found to be significantly higher, $3 \pm 5 \%$ (p<0.05), at the exposure with the best Raw. Consequently, the difference in Ret72 between exposures was, partly, explained by changes in Raw.

We found no significant correlation ( $\mathrm{p}>0.05)$ between Ret72 and the lung function parameters FEF75-85\% and $\mathrm{N}_{2}$-delta; FEF75-85\% (range 0.1-0.4, mean \pm SD 0.2 \pm 0.1 $\left.\mathrm{L} \cdot \mathrm{s}^{-1}\right)(\mathrm{r}=0.43)$, and $\mathrm{N}_{2}$-delta (range 2.1-14.4, mean $\left.6.1 \pm 3.1 \% \cdot \mathrm{L}^{-1}\right)(\mathrm{r}=-0.18)$. Introducing multiple stepwise regression analysis, including several lung function parameters (sRaw or Raw + FEF75-85\% + $\mathrm{N}_{2}$-delta), did not enhance the r-value substantially from $\mathrm{s} R$ aw or $R$ aw alone.

\section{Discussion}

The present study demonstrates the dynamic course of tracheobronchial clearance, i.e. the sum of $\mathrm{MC}$ and cough, in chronic bronchitis during 3 days, until the shortterm clearance phase is completed. This corresponds to the clearance course in real life, in contrast to most earlier investigations of $\mathrm{MC}$ performed in experimental conditions during a few hours [4-7, 24]. The fast clearance phase was practically at an end within $72 \mathrm{~h}$ in the present study, since between 48 and $72 \mathrm{~h}$ only about $3 \%$ of the inhaled particles were cleared. The Ret72 values, considered to represent the alveolar deposition fractions, were highly correlated at repeated exposures within the patients, and the small differences in Ret72 found between exposures could be explained, in part, by changes in lung function.

Earlier studies have demonstrated that MC is usually severely impaired in chronic bronchitis with or without COPD [4-7]. In spite of this, the fractions of rapidly cleared particles in the present study were found to be similar to those in healthy subjects [18]. This clearance is most likely due to a productive cough, but other mechanisms, such as compression of small bronchi and postural drainage, may also be relevant. An increased mucus production has been found to be important for the effectiveness of cough $[10,11,34]$; thus, cough is reported to be effective in cleaning tracer particles from the central airways of patients with increased amounts of secretion but not in healthy subjects $[11,12]$. Hypersecretion and cough are likely to be important compensation mechanisms for the impaired $\mathrm{MC}$ in chronic bronchitis, as has been shown to be the case in immotile-cilia syndrome $[2,13]$. Obviously, patients with immotilecilia syndrome can partly compensate for their profound ciliary defect by coughing; although surviving, they still suffer from a chronic airway disease and at times develop bronchiectasis and airways obstruction [2, 35].

Cough is thought to be most important in central airways where sufficiently high air velocities can be obtained, i.e. mainly between generation 0 and 7 [36]. One hypothesis in this study was that subjects with more tracheobronchial secretions would clear the inhaled particles in the central airways faster, due to a more effective cough. Although sputum weights correlated well intraindividually, and the amounts of expectorated sputum varied markedly among patients, there was no correlation between sputum weights and lung retentions after 24,48 and $72 \mathrm{~h}$. Thus, it seems that although increased secretions may be necessary for cough to be effective, a further increase above a certain level may be of little importance. An explanation for the discrepancy may be that the biochemical and physical properties are at least as important for clearance as the mere amount [37]. With the present method, it may be claimed that some of the expectorated material consisted of saliva. The subjects were, however, trained to avoid sampling saliva, and the reproducibility of sputum weights indicate that mainly sputum was collected. A further explanation for the lack of correlation could be that a relationship between clearance and the amount of secretion had been masked in some patients with small sputum volumes and a relatively well functioning MC. The design of our study was to investigate whether expectorated sputum volumes were correlated with the retention at the presumed endpoints of the fast clearance phase. Already at $24 \mathrm{~h}$ more than $80 \%$ of clearance was finished. Therefore, in a study aiming at determining the correlation between expectorated sputum volumes and tracheobronchial clearance extra measurements between 0 and $24 \mathrm{~h}$ might be needed.

Lung function derangements and airway obstruction are of crucial importance for the deposition of inhaled 
particles and the outcome of clearance measurements. We found significant correlations between Ret72 and lung function parameters reflecting the dimensions of larger airways ( $R$ aw and $\mathrm{s} R \mathrm{aw}$ ). These relationships agreed well with theoretical deposition data and with data found previously for healthy subjects. The regression lines were parallel, with quite similar retentions at corresponding values of airway resistance for the bronchitic patients and healthy subjects. It may seem questionable to compare the retention values of the bronchitic patients with values in healthy patients after stimulation of the mucociliary clearance by a cholinergic aerosol, but we believe that this is relevant. Firstly, we have previously shown that $6 \mathrm{~h}$ retention values in healthy persons are highly similar to the $24 \mathrm{~h}$ values when clearance is stimulated by a cholinergic aerosol [17, 18, 30, 33]. Secondly, as mentioned above, only a very small fraction of particles clears between 24 and $72 \mathrm{~h}$ in healthy subjects and in asthmatics $[15,20,21]$. An advantage in the present comparison between the chronic bronchitics and the healthy subjects is that the comparison is made at the same degree of bronchial obstruction. The relationship between $R$ aw and alveolar deposition particles is explained by the fact that airway anatomy controls penetration through the tracheobronchial tree, with an increased effect of impaction in larger airways when the diameters are decreased.

The relationships between $R$ aw and lung retentions representing alveolar deposition may be influenced by an increased functional residual capacity (FRC) in patients with bronchitis. This was, in fact, the case in the present study. Raw was measured at different FRC levels in healthy subjects and patients with bronchitis; whereas all subjects inhaled the test particles with maximally deep inhalations, about $70 \%$ of the vital capacity (VC), a procedure independent of FRC. The increased FRC in some patients with chronic airways obstruction explains quite well why $\mathrm{s} R$ aw was found to correlate better to lung retentions than $R$ aw.

These patients with bronchitis showed impairment of the lung function variables supposed to reflect dimensions of smaller airways (FEF75-85\% and $\mathrm{N}_{2}$-delta). We found no correlations between them and Ret72, nor did multiple regression analysis taking Raw or sRaw, FEF75-85\%, and $\mathrm{N}_{2}$-delta into account enhance the r-value compared to $R$ aw or $\mathrm{s}$ Raw alone. Our study, thus, gives no support to the view that changes in smaller airways in chronic bronchitic patients are important for deposition of particles of this order of size.

Although cough may, to a certain degree, compensate for a decreased mucociliary transport, the subjects with chronic bronchitis or COPD in this study did not have a normal airway clearance. Most particles were cleared within $24 \mathrm{~h}$, but there was a small but significant fraction cleared between 24 and $72 \mathrm{~h}$, in contrast to the results of earlier studies on healthy subjects or asthmatics, where no such clearance was detected $[15,20,21]$. These findings suggest that persons with chronic bronchitis not only have an impaired mucociliary transport, but also a slower total mucus clearance course, at least locally, perhaps in small airways where cough may be less effective. This altered clearance pattern may cause a longer local retention of noxious particles and increase the risk of respiratory complications, such as infections, compared to normal subjects. Moreover, inhaled particles may deposit at different levels at the airway surface. Particles deposited on the top of excessive bronchial secretions may easily be coughed up, whilst particles deposited at the epithelial level may be insufficiently cleared by the mucociliary transport system, contributing to the prolonged clearance found here. After all, we only measure a rather rough total sum of airway mucus clearance. It should be noted that our clearance observations were made in patients with chronic bronchitis, usually taking bronchodilator medication. Several bronchodilating drugs, such as beta-agonists [5], are reported to be able to stimulate the mucociliary transport system under certain circumstances. The medication was kept unchanged during the study and probably did not influence the present results.

In conclusion, in contrast to earlier findings that mucociliary transport is usually impaired in chronic bronchitis and COPD, the present results indicate that overall tracheobronchial mucus clearance in these patients is fairly effective, probably due to a productive cough. Our results also suggest that alveolar deposition of $3.6 \mu \mathrm{m}$ particles can be estimated by measurements of the lung retention at $72 \mathrm{~h}$ in COPD, and that this retention is, to a great extent, dependent on the calibre of larger airways. Finally, we were able to demonstrate a high degree of reproducibility of the present method of studying tracheobronchial clearance during the comparatively long time-period of 3 days. The retentions at all time-points at the two different clearance measurements correlated well. The reproducible results will encourage us to use this method as a model for future studies on clearance in airway diseases and on the possible influence by pharmacological agents, such as mucolytic or expectorant drugs.

Acknowledgements: The authors thank M. Anderson, for help with figures, U. Bergsten, K. Widtskiöld-Olsson, and B. Nilsson for expert technical assistance.

\section{References}

1. Eliasson R, Mossberg B, Camner P, Afzelius B. The immotile-cilia syndrome: a congenital ciliary abnormality as an etiological factor in chronic ariway infections and male sterility. N Engl J Med 1977; 297: 1-6.

2. Mossberg B, Afzelius BA, Eliasson R, Camner P. On the pathogenesis of obstructive lung disease: a study on the immotile-cilia syndrome. Scand J Respir Dis 1978; 59: 55-65.

3. Camner P, Mossberg B. Mucociliary disorders: a review. J Aerosol Med 1988; 1: 21-28.

4. Camner P, Mossberg B, Philipson K. Tracheobronchial clearance and chronic obstructive lung disease. Scand $J$ Respir Dis 1973; 54: 272-281.

5. Mossberg B, Strandberg K, Philipson K, Camner P. Tracheobronchial clearance and beta-adrenoceptor stimulation in patients with chronic bronchitis. Scand J Respir Dis 1976; 57: 281-289. 
6. Goodman RM, Yergin BM, Landa JF, Golinvaux MH, Sackner MA. Relationship of smoking history and pulmonary function tests to tracheal mucous velocity in nonsmokers, young smokers, ex-smokers and patients with chronic bronchitis. Am Rev Respir Dis 1978; 117: 205-214.

7. Matthys H, Vastag E, Köhler D, Daikeler G, Fisher J. Mucociliary clearance in patients with chronic bronchitis and bronchial carcinoma. Respiration 1983; 44: 329-337.

8. Camner P, Philipson K. Tracheobronchial clearance in smoking discordant twins. Arch Environ Health 1972; 25: 60-63.

9. Vastag E, Matthys H, Zsamboki G, Khöler D, Daikeler G. Mucociliary clearance in smokers. Eur J Respir Dis 1986; 68: 107-113.

10. Yeates D, Sturgess J, Kahn S, Levison H, Aspin N. Mucociliary transport in trachea of patients with cystic fibrosis. Arch Dis Child 1976; 51: 28-33.

11. Camner P, Mossberg B, Philipson K, Strandberg K. Elimination of test particles from the human tracheobronchial tract by voluntary coughing. Scand J Respir Dis 1979; 60: 56-62.

12. Puchelle E, Zahm JM, Girard F, et al. Mucociliary transport in vivo and in vitro: relations to sputum properties in chronic bronchitis. Eur J Respir Dis 1980; 61: 254-264.

13. Ruusa J, Svartengren M, Philipson K, Camner P. Tracheobronchial particle deposition and clearance in immotile-cilia syndrome patients. J Aerosol Med 1993; 6: 89-97.

14. Lippmann M, Albert RE, Peterson HT. The regional deposition of inhaled aerosols in man. In: Walton $\mathrm{WH}$, ed. Inhaled Particles. III. Surrey, Unwin Bros Ltd, 1971; pp. 105-120.

15. Camner P, Philipson K. Human alveolar deposition of $4 \mu \mathrm{m}$ Teflon particles. Arch Environ Health 1978; 33: 181-185.

16. Svartengren M, Linnman L, Philipson K, Camner P. Regional deposition in human lung of $2.5 \mu \mathrm{m}$ particles. Exp Lung Res 1987; 12: 265-279.

17. Svartengren M, Philipson K, Camner P. Individual differences in regional deposition of $6 \mu \mathrm{m}$ particles on induced bronchoconstriction. Exp Lung Res 1989; 15: 139-149.

18. Svartengren M, Anderson M, Philipson K, Camner P. Human lung deposition of particles suspended in air or in helium/oxygen mixture. Exp Lung Res 1989; 15: $575-585$.

19. Svartengren M, Philipson K, Linnman L, Camner P. Airway resistance and deposition of particles in the lung. Exp Lung Res 1984; 7: 257-269.

20. Svartengren M, Anderson M, Bylin G, Philipson K, Camner P. Regional deposition of $3.6 \mu \mathrm{m}$ particles in subjects with mild to moderately severe asthma. J Aerosol Med 1990; 3: 197-207.

21. Svartengren M, Anderson M, Bylin G, Philipson K,
Camner P. Regional deposition of $3.6 \mu \mathrm{m}$ particles and lung function in asthmatic subjects. J Appl Physiol 1991; 71(6): 2238-2243.

22. Anderson M, Svartengren M, Bylin G, Philipson K, Camner P. Deposition in asthmatics of particles inhaled in air or helium-oxygen. Am Rev Respir Dis 1993; 147: 524-528.

23. Anderson M, Svartengren M, Philipson K, Camner P. Deposition in man of particles inhaled in air or heliumoxygen mixture at different flow rates. J Aerosol Med 1990; 3: 209-216.

24. Pavia D, Agnew JE, Glassman JM, et al. Effects of iodopropylidene glycerol on tracheobronchial clearance in stable, chronic bronchitic patients. Eur J Respir Dis 1985; 67: 177-184.

25. Agnew JE, Bateman JRM, Watts M, Paramananda V, Pavia D, Clarke SW. The importance of aerosol penetration for lung mucociliary clearance studies. Chest 1981; 80 (Suppl.): 843-846.

26. Medical Research Council. Definition and classification of chronic bronchitis for clinical and epidemiological purposes. Lancet 1965; i: 775-781.

27. Quanjer PH (ed.). European Coal and Steel Community. Standardized lung function testing. Bull Eur Physiopathol Respir 1983; 19 (Suppl. 5).

28. Camner P. The production and use of test aerosols for studies of human tracheobronchial clearance. Environ Physiol Biochem 1971; 1: 137-154.

29. Philipson K. Monodisperse labelled aerosols for studies of lung clearance. In: Abstracts of Uppsala. Dissertations from the Faculty of Science 433. Uppsala, Sweden, 1977; pp. 1-36.

30. Svartengren M, Falk R, Linnman L, Philipson K, Camner P. Deposition of large particles in human lung. Exp Lung Res 1987; 12: 75-88.

31. Svartengren M, Andersson M, Bylin G, Philipson K, Camner P. Mouth and throat deposition of $3.6 \mu \mathrm{m}$ radiolabelled particles in asthmatics. J Aerosol Sci 1991; 4: 313-321.

32. Task Group on Lung Dynamics. Deposition and retention models for internal dosimetry of the human respiratory tract. Health Phys 1966; 12: 173-207.

33. Svartengren M, Philipson K, Linnman L, Camner P. Regional deposition of particles in human lung after induced bronchoconstriction. Exp Lung Res 1986; 10: 223-233.

34. Yeates D, Aspin N, Levinson H, Jones M, Byran AC. Mucociliary tracheal transport rates in man. $J$ Appl Physiol 1975; 39: 487-495.

35. Mossberg B, Camner P, Afzelius BA. The immotilecilia syndrome compared to other obstructive lung diseases: a clue to their pathogenesis. Eur J Respir Dis 1983; 64 (Suppl. 127): 129-136.

36. Leith DE. Cough. Phys Ther 1968; 48: 439-447.

37. Scherer PW. Mucus transport by cough. Chest 1981; 80 (Suppl.): 830-833. 